\title{
Analysis of the Hypervariable Regions (HVRs) of the wsp Gene of Wolbachia from Solenopsis invicta Ants in Southeastern Brazil
}

\author{
Rodrigo Fernando de Souza ${ }^{1 *}$, Cíntia Martinss ${ }^{2}$, Roberto Manoel Pereira ${ }^{3}$, \\ Odair Correa Bueno ${ }^{1}$ \\ ${ }^{1}$ Centro de Estudos de Insetos Sociais, Instituto de Biociências, Universidade Estadual Paulista Julio de \\ Mesquita Filho, Campus Rio Claro, São Paulo, Brazil \\ ${ }^{2}$ Universidade Federal do Piauí (Federal University of Piauí), Campus Parnaíba, Piauí, Brazil \\ ${ }^{3}$ Urban Entomology Laboratory, Entomology \& Nematology Department, University of Florida, \\ Gainesville, USA \\ Email: souza bio@yahoo.com.br, martins.c@ufpi.edu.br, rpereira@ufl.edu, odaircb@rc.unesp.br
}

Received 27 April 2014; revised 30 May 2014; accepted 24 June 2014

Copyright (C) 2014 by authors and Scientific Research Publishing Inc.

This work is licensed under the Creative Commons Attribution International License (CC BY).

http://creativecommons.org/licenses/by/4.0/

(c) (i) Open Access

\begin{abstract}
Wolbachia is a bacterium that infects many arthropods with horizontal or vertical transmission. The introduction and spreading of Solenopsis invicta in new areas may have influenced the acquisition of Wolbachia as this ant species spread from its South America origin to other parts of the globe. The wsp gene of Wolbachia was analyzed using the WSP Typing and a similarity analysis was conducted to analyse the sharing of the symbiont among nests of $S$. invicta ants. The analyses revealed the presence of two groups of Wolbachia: strain A belonging to InvA S. invicta subgroup, and the strain B belonging to Acromyrmex insinuator. The wsp gene and its hypervariable regions are shared among the Wolbachia present in different types of ants inhabiting in the New World. Wolbachia strains found in the nests of $\boldsymbol{S}$. invicta are ant-specialist symbionts which may have spread by several means among the ant population.
\end{abstract}

\section{Keywords}

Ant, Recombination, Horizontal Transmission, Symbiont

\footnotetext{
${ }^{*}$ Corresponding author.
}

How to cite this paper: de Souza, R.F., Martins, C., Pereira, R.M. and Bueno, O.C. (2014) Analysis of the Hypervariable Regions (HVRs) of the wsp Gene of Wolbachia from Solenopsis invicta Ants in Southeastern Brazil. Advances in Entomology, 2, 135-143. http://dx.doi.org/10.4236/ae.2014.23021 


\section{Introduction}

Wolbachia is an intracellular bacterium that belongs to the group of $\alpha$-proteobacteria and infects a large number of hosts such as insects, crustaceans, chelicerates and nematodes. Studies suggest that infection by Wolbachia may affect as many as $65 \%$ of insect species [1]. Infection by Wolbachia can cause various effects in its hosts such as feminization, local adaption, speciation and cytoplasmic incompatibility (CI) [2]. CI has been associated with asynchrony of endomitotic divisions, resulting in nonviable embryos [3].

Wolbachia infections have been divided into eight supergroups-A, B, C, D, E, F, G and H, based on the many phylogenetic analyses using sequences from several genes (16S rDNA, wsp, ftsZ, groEL, gltA and dnaA) [4]. Transmission of Wolbachia can occur vertically, via the cytoplasm of the female reproductive cells, or horizontally, due to interactions between different taxa [5] [6].

Wolbachia infection of $S$. invicta populations has occurred six different times via horizontal transmission [7], but there have been multiple infections and independent loses. These researchers also noted that significant variation in the prevalence of the Wolbachia infection can be caused by regional limits, environment factors and loss of infection by hosts. The frequency of infection by Wolbachia in native populations of S. invicta can vary among distinct geographic populations and between nests exhibiting different social forms [8].

The Wolbachia variants found in New World ants are similar to each other, but differ from other variants that occur in other insect groups, suggesting that they are specialized to ants [9]. There are differences between the strains found in ants and those found in other insect groups as well as between strains that occur in New World and Old World ants [10].

Recombination between different strains of Wolbachia can occur [11], leading to increased variability and promoting the rise of new variants and development of novel phenotypes. These recombination regions, hypervariable regions (HVRs), of the wsp gene of Wolbachia can undergo recombination within the same strain or between different strains. The HVRs are subject to positive selection, and genetic recombination can play a major role in the host-parasite interactions and in changes in the functional characteristics of the surviving of Wolbachia. The WSP Typing can be used for molecular characterization of HVRs and study of recombination in wsp of Wolbachia.

In this study, we analyzed HVRs of wsp gene of Wolbachia found in S. invicta using WSP Typing to determine the occurrence of recombination among the variants of Wolbachia found in ant nests. Phylogenetic and similarity analyses were conducted using data on the wsp gene for verification of the horizontal transmission of Wolbachia variants.

\section{Materials and Methods}

\subsection{Collection and Preservation}

Solenopsis invicta nests (soil and all castes) were collected using methods describe in Banks et al. [12], in two different locations (P1 and P2) in each of the cities of Salesópolis, Mogi das Cruzes, São Paulo, Campinas, and Rio Claro, in São Paulo state, Brazil. The ant samples were preserved in $80 \%$ ethanol and stored in a $-20^{\circ} \mathrm{C}$ freezer. The geographic coordinates for each position were recorded (Table 1).

\subsection{DNA Extraction and mtDNA Sequencing}

Ant samples were homogenized in lysis buffer consisting of $100 \mathrm{mM}$ Tris (pH 9.1), $100 \mathrm{mM} \mathrm{NaCl,} 50 \mathrm{mM}$ EDTA and $0.5 \%$ SDS. The homogenized samples were incubated at $55^{\circ} \mathrm{C}$ for $3 \mathrm{~h}$ and protein residues were precipitated with $5 \mathrm{M} \mathrm{NaCl}$. DNA was precipitated from samples using $100 \%$ ethanol, followed by $70 \%$ ethanol. DNA was eluted with TE buffer (10 mM Tris, 1 mM EDTA, pH 8.0). PCR amplification of mtDNA was conducted using methods described by Ahrens et al. [13] using primers C1-J-2195 and DDS-COII-4, which amplify a region of approximately 920 bp of the cytochrome oxidase I (COI) gene. Sequencing of samples was conducted using an ABI 3130 Genetic Analyzer (Applied Biosystems ${ }^{\mathrm{TM}}$ ).

\subsection{Identification}

Ant species identification was conducted based on the cytochrome oxidase I (COI) gene using the Barcode method [14]-[17]. The mtDNA sequences (approximately 920-bp region of the cytochrome oxidase I) were ana- 
Table 1. Samples of Wolbachia from S. invicta from different cities in São Paulo State, Brazil.

\begin{tabular}{|c|c|c|}
\hline Locations & Geographic coordinates & $\begin{array}{l}\text { Similar haplotypes of } \\
\text { S. invicta in GenBank }\end{array}$ \\
\hline Mogi das Cruzes P1 & $23^{\circ} 31^{\prime} 07.12^{\prime \prime S} 46^{\circ} 10^{\prime} 58.60^{\prime \prime} \mathrm{W}$ & 39 \\
\hline Mogi das Cruzes P2 & $23^{\circ} 31^{\prime} 07.84^{\prime \prime S} 46^{\circ} 10^{\prime} 58.92^{\prime \prime} \mathrm{W}$ & 40 \\
\hline Rio Claro P1 & $22^{\circ} 23^{\prime} 50.18^{\prime \prime} \mathrm{S} 47^{\circ} 32^{\prime} 56.03^{\prime \prime} \mathrm{W}$ & Lu-Chuan \\
\hline Rio Claro P2 & $22^{\circ} 23^{\prime} 49.00^{\prime \prime S} 47^{\circ} 32^{\prime} 55.51^{\prime \prime} \mathrm{W}$ & 40 \\
\hline São Paulo P1 & $23^{\circ} 33^{\prime} 36.69^{\prime \prime} \mathrm{S} 46^{\circ} 42^{\prime} 47.65^{\prime \prime} \mathrm{W}$ & 47 \\
\hline São Paulo P2 & $23^{\circ} 33^{\prime} 37.18^{\prime \prime S} 46^{\circ} 42^{\prime} 48.66^{\prime \prime} \mathrm{W}$ & 41 \\
\hline Salesópolis P1 & $23^{\circ} 32^{\prime} 00.03^{\prime \prime S} 45^{\circ} 50^{\prime} 55.46^{\prime \prime} \mathrm{W}$ & 47 \\
\hline Salesópolis P2 & $23^{\circ} 31^{\prime} 46.11^{\prime \prime S} 45^{\circ} 51^{\prime} 03.86^{\prime \prime} \mathrm{W}$ & 41 \\
\hline Campinas P2 & $22^{\circ} 49^{\prime} 14.01^{\prime \prime S} 47^{\circ} 03^{\prime} 37.47^{\prime \prime} \mathrm{W}$ & 47 \\
\hline Campinas P3 & $22^{\circ} 49^{\prime} 21.43^{\prime \prime S} 47^{\circ} 03^{\prime} 41.78^{\prime \prime} \mathrm{W}$ & 49 \\
\hline
\end{tabular}

*All the haplotypes presented 99\% similarity to similar haplotypes of S. inivcta in GenBank. The E-value was 0.0 for all sequences.

lyzed with Bioedit software [18] and compared with sequences in the National Center for Biotechnology Information (NCBI) database via BLAST searches (http://blast.ncbi.nlm.nih.gov/Blast.cgi). To ensure reliability in the identification of ants, we used five ants from each nest, and their mtDNA was sequenced and analyzed separately. Ten nests positively identified as $S$. invicta were selected, and their respective values of similarity and E-values were determined (Table 1).

\subsection{Social Form}

The ten S. invicta nests were also analyzed to determine their social form (monogyne or polygyne). We used two sets of primers, 26BS and 16BAS; 24bS and 25bAS as describes in Valles and Porter [19], and two other sets of primers (Gp-9.for and Gp-9.rev; all_b.rev and all_b.for) as describes in Ross et al. [20]. Five ants from each nest were tested and the analyses were conducted in duplicate.

\subsection{Wolbachia}

Thirty ants from each nest were examined to verify infection by Wolbachia. PCR assays were performed using the wsp81F and wsp691R primers to amplify a region of approximately 590 bp of the wsp gene [21]. Sequencing of the samples was carried out with an ABI 3130 Genetic Analyzer (Applied Biosystems ${ }^{\mathrm{TM}}$ ).

\subsection{Similarity and Phylogenetic Analyses}

The similarities of the sequences were analyzed via Neighbor-joining method using Mega 4.0 software [22]. Branch distances were calculated using Kimura's 2-parameter model and the reliability of the branches was measured via bootstrap analysis (2000 replicates). Bayesian phylogenetic analysis was conducted using MrBayes software [23]. The GTR $+G$ model was selected and the Markov chain was run for 1,000,000 generations sampled every 100 generations. The first $10 \%$ of the trees were excluded, and the subsequent probability values were calculated using the remaining trees assuming a mid point rooting [17].

For comparison purposes, we included in the analyses Wolbachia sequences previously detected in S. invicta and provided by Dr. David Dewayne Shoemaker from the Center for Medical Agricultural and Veterinary Entomology, USDA-ARS, USA. Among these sequences, two were from ants collected in Formosa, two from Roldan, two from Corrientes, and two from Rosario, all in Argentina and two sequences were from S. invicta from the USA. Twenty-two additional Wolbachia sequences were obtained from NCBI. Furthermore, five sequences were provided by researcher Ms. Cíntia Martins from Universidade Federal do Piauí, PI, Brazil, namely: Registro-SP P1, Registro-SP P2 and Ubatuba-SP P1, in InvA subgroup, and Picinguaba-SP P1, Registro-SP P1, in InvB subgroup. These sequences were deposited in GenBank together with the sequences obtained in this 
study. A phylogenetic tree was generated by Mega 4.0 software and MrBayes software, but there were no significant differences between trees generated by the two softwares.

\section{WSP Typing}

For analysis of the HVRs in the wsp gene, the WSP Typing (online tool:

http://pubmlst.org/wolbachia/wsp/info/wsp_typing.shtml) was used and sequences were compared to sequences deposited in the PubMLST Wolbachia wsp database (http://pubmlst.org/wolbachia/wsp). This online tool verifies the HVRs alleles of the wsp gene (obtained in the study) and compares them with the alleles found in the wsp gene from other organisms. The results of the analysis can indicate whether the wsp gene sequence is the result of recombination among strains. The different alleles found in the HVRs are indicated with numbers in tables.

\section{Results}

\subsection{Mitochondrial DNA and Social Form}

We observed only one lineage of mtDNA haplotypes per $S$. invicta nest (Table 1 ). The social form analyses showed that all of the investigated nests exhibited monogyny.

\subsection{Wolbachia}

Only 5 nests out of 10 sampled were infected with Wolbachia: 2 nests from Rio Claro, and 1 nest each from Salesópolis, Campinas, and Mogi das Cruzes. Two nests from São Paulo were not infected with the symbiont. The sequences were deposited in the NCBI database under the following accession numbers and names: WolbachiaA-UbatubaSPP1 JQ425780, Wolbachia-A-RegistroSPAP1 JQ425781, Wolbachia-A-RegistroSPP2 JQ425782, Wolbachia-A-Rio-ClaroSPP1 JQ425783, Wolbachia-A-Rio-ClaroSPP2 JQ425784, Wolbachia-A SalesopolisSPP1 JQ425785, Wolbachia-A-CampinasSPP1 JQ425786, Wolbachia-B-RegistroSPP1 JQ425787, Wolbachia-B-PicinguabaSPP1 JQ425788 and Wolbachia-B-MogidasCruzesSPP1 JQ425789.

Wolbachia wsp sequences from ants obtained from nests from São Paulo state and provided by Dr. Shoemaker had 99\% identity with samples in Gene Bank. Samples from Salesópolis, Rio Claro and Campinas were similar to group A, subgroup InvA: specifically wSinvictaA-AF243435.1 of Wolbachia from S. invicta. Sequence from Mogi das Cruzes was similar to group $B$, subgroup B2: specifically A. insinuator-AF472560, of Wolbachia from Acromyrmex insinuator. Four of the sequences provided by Dr. Shoemaker were similar to group $B$, subgroup InvB: specifically wSinvictaB-AF243436.1 of Wolbachia from S. invicta whereas the other four sequences were similar to group A, subgroup InvA: specifically wSinvictaA-AF243435.1 of Wolbachia from S. invicta. The three of the sequences obtained from Ms. Cintia Martins were similar to group $A$, subgroup InvA, while the other two were similar to group $B$, subgroup B2: specifically from $A$. insinuator. None of the sampled nests showed multiple Wolbachia infections.

\subsection{Phylogenetic and Similarity Analyses}

There were no differences between the results of the phylogenetic and similarity analyses of the wsp gene of Wolbachia. The phylogenetic tree resulting from the similarity analysis of the wsp gene of Wolbachia (Figure 1) revealed no differences among the Wolbachia sequences in InvA subgroup. Our samples in InvA subgroup form a polytomy with all of the sequences provided by other researchers and the sequences obtained from GenBank. The lack of resolution is reflected in the low bootstrapping value for each clade. The Wolbachia samples from Linepithema humile (from GenBank) were also included within InvA subgroup, and the S. saevissima-S1 and SS2 (from GenBank), sequences grouped with a sister clade to subgroup InvA. The Wolbachia sequences from the other Solenopsis species (S. daguerrei and S. richteri) from GenBank form three clades within Wolbachia group $A$.

\subsection{WSP Typing}

Some sequences of $\operatorname{InvA}$, InvB subgroups and $B$ group showed partial values in the analysis, these sequences were not $100 \%$ identical to the deposited sequences in the PubMLST Wolbachia wsp database, but when the sequences showed partial values for one allele, it was accepted. Sequences that showed partial values for several alleles were not accepted, but the alleles are shown in Table 2. 


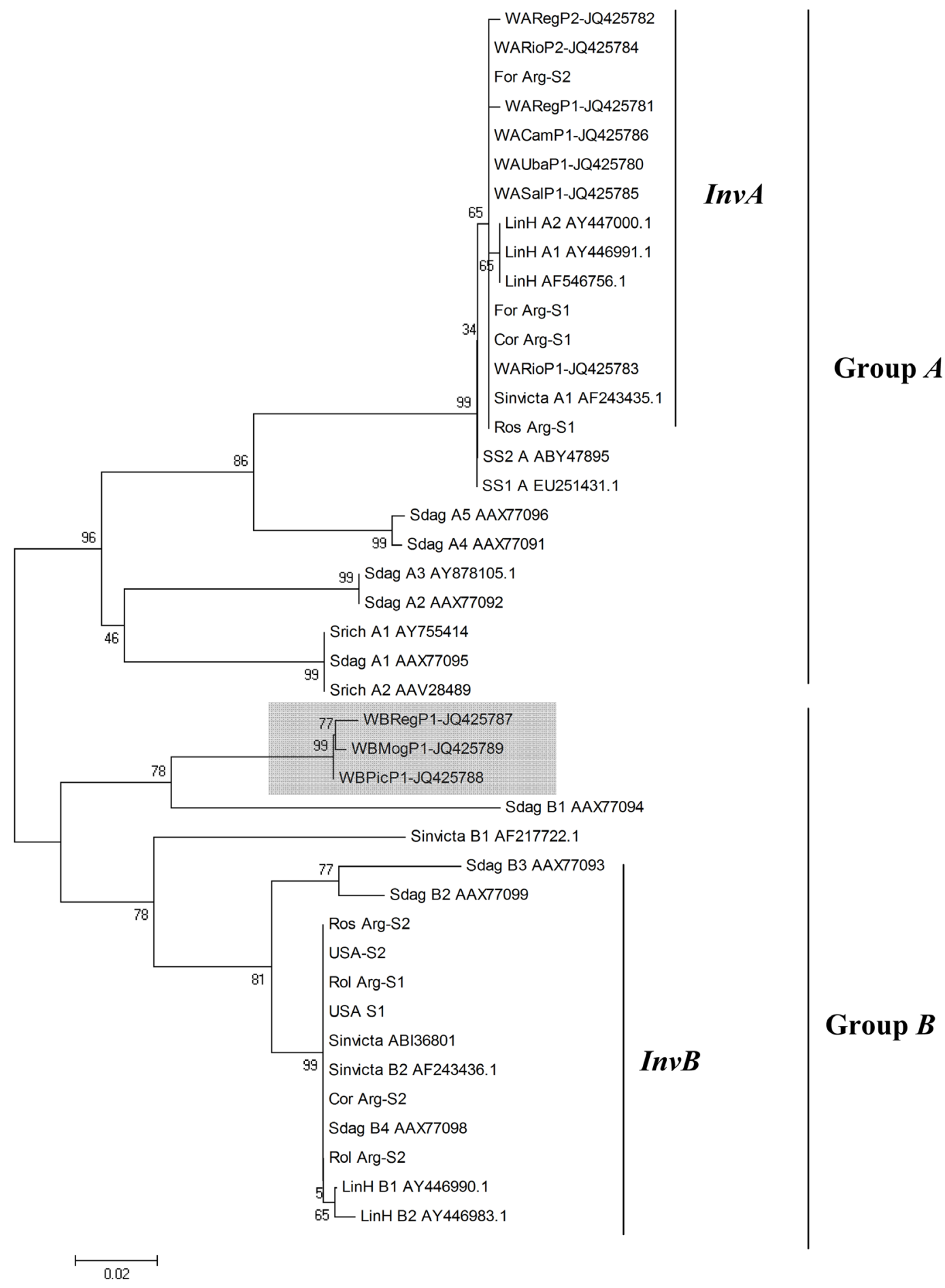

Figure 1. Phylogenetic tree of wsp from Wolbachia obtained from different populations. The gray box indicates the sequences of the Wolbachia of the A. insinuator found in nest of the S. inivicta. The illustrated tree was generated by software Mega 4.0. The bootstrap values are showed previously of the branches. The sequence names were shortened to the better arrangement in the figure.

The sequences of InvA subgroup of Wolbachia from S. invicta nest collected for this study showed the following alleles: HVR1-allele 42; HVR2-allele 43; HVR3-allele 198; and HVR4-allele 25. The sequences from Argentina shared the same alleles for the HVR1, HVR2 and HVR3 with S. invicta nests collected, but showed 
Table 2. Alleles (numbers according to PubMLST Wolbachia wsp database) present as complete sequences (in orange cells), partial sequences (in gray cells) in shared HVR's of wsp gene in the InvA and InvB subgroup and B group of Wolbachia from Solenopsis invicta samples collected in São Paulo state, Brazil, and other ant samples.

\begin{tabular}{|c|c|c|c|c|c|}
\hline \multirow{2}{*}{ Sequence source/identification ${ }^{*}$} & \multicolumn{4}{|c|}{ Alleles } & \multirow{2}{*}{$\begin{array}{c}\text { Group or subgroup of } \\
\text { Wolbachia }\end{array}$} \\
\hline & HVR1 & HVR2 & HVR3 & HVR4 & \\
\hline WAUbaP1-JQ425780 & 42 & 43 & 198 & 25 & $\operatorname{InvA}$ \\
\hline WARegP1-JQ425781 & 42 & 43 & 198 & 25 & $\operatorname{Inv} A$ \\
\hline WARegP2-JQ425782 & 42 & 43 & 198 & 25 & $\operatorname{InvA}$ \\
\hline WARioP1-JQ425783 & 42 & 43 & 198 & 25 & $\operatorname{Inv} A$ \\
\hline WARioP2-JQ425784 & 42 & 43 & 198 & 25 & $\operatorname{InvA}$ \\
\hline WASalP1-JQ425785 & 42 & 43 & 198 & 25 & $\operatorname{Inv} A$ \\
\hline WACamP1-JQ425786 & 42 & 43 & 198 & 25 & $\operatorname{Inv} A$ \\
\hline For_Arg-S1 & 42 & 43 & 198 & Unidentified & $\operatorname{Inv} A$ \\
\hline For_Arg-S2 & 42 & 43 & 198 & Unidentified & $\operatorname{InvA}$ \\
\hline Ros_Arg-S1 & 42 & 43 & 198 & Unidentified & $\operatorname{InvA}$ \\
\hline Cor_Arg-S1 & 42 & 43 & 198 & Unidentified & $\operatorname{InvA}$ \\
\hline Lhum A AY446991.1 & 42 & 43 & 198 & Unidentified & $\operatorname{InvA}$ \\
\hline Lhum A AY447000.1 & 42 & 43 & 198 & Unidentified & $\operatorname{Inv} A$ \\
\hline Lhum A AF546756 & 42 & 43 & 198 & 25 & $\operatorname{Inv} A$ \\
\hline Sdag B2 AXX77099 & 1 & 21 & 25 & 21 & $\operatorname{Inv} B$ \\
\hline Sdag B3 AXX77093 & 66 & 21 & 25 & 21 & $\operatorname{Inv} B$ \\
\hline Sdag B2 AXX77098 & 21 & 21 & 25 & 21 & $\operatorname{InvB}$ \\
\hline Sinv B2 AF243436 & 21 & 21 & 25 & 21 & $\operatorname{InvB}$ \\
\hline Sinv ABI36801 & 21 & 21 & 25 & 21 & $\operatorname{InvB}$ \\
\hline Lhum B2 AY446983.1 & 21 & 21 & 25 & Unidentified & $\operatorname{Inv} B$ \\
\hline Lhum B1 AY446990.1 & 21 & 21 & 25 & Unidentified & $\operatorname{Inv} B$ \\
\hline Rol_Arg-S1 & 21 & 21 & 25 & Unidentified & $\operatorname{InvB}$ \\
\hline USA_S1 & 21 & 21 & 25 & Unidentified & $\operatorname{Inv} B$ \\
\hline USA-S2 & 21 & 21 & 25 & Unidentified & $\operatorname{Inv} B$ \\
\hline Rol_Arg-S2 & 21 & 21 & 25 & Unidentified & $\operatorname{Inv} B$ \\
\hline Cor_Arg-S2 & 21 & 21 & 25 & Unidentified & $\operatorname{Inv} B$ \\
\hline Ros_Arg-S2 & 21 & 21 & 25 & Unidentified & $\operatorname{Inv} B$ \\
\hline WBMogP1-JQ425789 & 21 & 40 & 48 & Unidentified & $B$ \\
\hline WBRegP1-JQ425787 & 21 & 40 & 42 & Unidentified & $B$ \\
\hline WBPicP1-JQ425788 & 21 & 40 & 42 & Unidentified & $B$ \\
\hline
\end{tabular}

* The sequence names were shortened to the better arrangement in the table. 
partial results for many alleles of the HVR4. Some sequences obtained from GenBank presented partial results for just one allele in the HVRs, so these alleles were accepted. The other sequences had undefined alleles for HVR4 (Table 2). Some sequences from $B$ group and the other sequences from InvB subgroup of the wsp gene from Wolbachia also showed partial values in the analysis of alleles.

The three Wolbachia sequences from $S$. daguerrei (obtained from GenBank) had a different allele within HVR1. The $S$. dagB2 sequence exhibited allele 1, whereas SdagB3 sequence had allele 66, and SdagB4 sequence had allele 21. All other remaining sequences of the $B$ group and InvB subgroup of Wolbachia had allele 21 in HVR1 including Mogi das Cruzes, Picinguaba and Registro. The sequences of Wolbachia from these cities presented the allele 40 for the HVR2 whereas all sequences of the InvB subgroup presented allele 21, see Table 2. All sequences of the $I n B$ subgroup presented the allele 25 for the HVR3, and the sequences of the $B$ group of Wolbachia from Picinguaba and Registro presented the allele 42. The sequence from Mogi das Cruzes presented the allele 48 of the HVR3. Some sequences from the GenBank presented the allele 21 for the HVR4, but for other sequences the alleles could not be defined (Table 2).

\section{Discussion}

Several factors influence Wolbachia infection of ant nests including microgeographic variation, environmental factors or intrinsic characteristics of the hosts [7]. We estimated 50\% infection rate in the sampled S. invicta mounds which is probably due to Wolbachia-infected and uninfected $S$. invicta queens invading new areas, generating infected and uninfected nests [7] [8] [24] [25]. A previous study [24], found $10 \%$ to $90 \%$ prevalence of Wolbachia infection in native populations of S. invicta. The prevalence observed in this study corroborates former studies in native populations of fire ants.

Sharing of Wolbachia in the same subgroup ( $\operatorname{InvA}$ ) by different ant species may indicate a high capacity for Wolbachia transmission, possibly due to a loss of specialization in the symbiont, resulting in the infection a large group of insect (ants) with similar biological and ecological characteristics. Such a phenomenon would proportionally and numerically increase the local survival of the symbiont, and supports the hypothesis of a symbiont specialized in ants [9]. Because L. humile and different species of Solenopsis and Acromyrmex share the same Wolbachia subgroups InvA and InvB [6] [26], specialization to ants by the symbiont seems entirely possible. Wolbachia subgroups InvA and InvB (Figure 1) seem to be specific to New World ants [9].

The mechanism to explain the results in sharing of Wolbachia subgroup (InvA) among ant species can be horizontal transmission via social parasites [6], or parasitoids, such as the flies Pseudacteon genus or wasps of the Diapriidae family [26]. However, other mechanisms such as vertical transmission, loss and reintroduction of infection, populations structure, distinct behaviors and the spreading and radiation of populations [7] may also be important in the phylogenetic grouping we report here for Wolbachia A groups.

The high diversity of sympatric species of ants found in South America may have contributed to the generalist adaptation of Wolbachia. The energetic expenditure required for a symbiont to develop highly specialized relationship with a single host may be too high and may have serious implications for the survival of the symbiont. The advantage of low host-specialization and consequently a lower energy requirement may increase the local survival of a symbiont, and thus explain the sharing of the same subgroups of Wolbachia by different groups of New World ants.

The infection of $S$. invicta by strain $B$ of Wolbachia from $A$. insinuator may also represent a generalist adaptation of the symbiont. However, other possible explanations such as horizontal transmission, transmission via parasitoids, close relationship between sympatric populations of $A$. insinuator and $S$. invicta, close relationship between $S$. daguerrei (social parasite of $S$. invicta) and A. echinatior (social host of A. insinuator) may also result in the acquisition and subsequent transmission of symbiont infection. The proximity of sequences for Wolbachia samples between $S$. daguerrei B1 and A. insinuator as displayed in the phylogenetic tree, may indicate an interaction between these ant species.

The partial sequences observed in the wsp gene may be due to punctual mutations in the sequences, or the sequences not being of an appropriate size for the analysis, both of which would interfere with the identity of the alleles. However, the great diversity of the alleles of HVR1 sequences Wolbachia from S. daguerrei may be due to social parasite behavior of this ant, which can facilitate multiple infections by different Wolbachia strains in only a single individual $S$. daguerrei [6], and consequent recombination of HVRs of the wsp gene. Baldo et al. [11] hypothesized that the recombination of HVRs of the wsp gene can produce new phenotypes for the sym- 
biont and this can be selectively advantageous. Superinfection may provide genetic material for recombination in the HVRs resulting in new allele variants, which can be disseminated by the social parasitic ant. Sharing of HVR2, HVR3 and HVR4 alleles with sequences belonging to the InvB subgroup of Wolbachia is likely an indication for the occurrence of horizontal transmission via social parasite.

\section{Conclusion}

Although an ant-specific Wolbachia strain would have a greater chance for survival and establishment in new niches, the increased energetic expenditure required to infect new hosts would be disadvantageous for the bacterium and has potential consequences for its survival. This study sheds new light on the variability of Wolbachia HVRs, its role on the occurrence of recombined Wolbachia strains naturally found in ants, and potential effects of these new symbiontic relationships on the biology of both the hosts and symbionts.

\section{Acknowledgements}

We acknowledge the post graduate program on Molecular and Cellular Biology of the Universidade Estadual Paulista Julio de Mesquita Filho (UNESP) for the scientific contributions to this research. We also thank the Coordenação de Aperfeiçoamento de Pessoal de Nível Superior (CAPES) for the financial support to the first author and Dr. David Dewayne Shoemaker (Center for Medical, Agricultural and Veterinary Entomology, USDA-ARS, Gainesville, FL, USA) for the material provided.

\section{References}

[1] Hilgenboecker, K., Hammerstein, P., Schlattmann, P., Telschow, A. and Werren, J.H. (2008) How Many Species Are Infected with Wolbachia? A Statistical Analysis of Current Data. FEMS Microbiology Letters, 281, 215-220. http://dx.doi.org/10.1111/j.1574-6968.2008.01110.x

[2] Stouthamer, R., Breeuwer, J.A.J. and Hurst, G.D.D. (1999) Wolbachia Pipientis: Microbial Manipulator of Arthropod Reproduction. Annual Review of Microbiology, 53, 71-102. http://dx.doi.org/10.1146/annurev.micro.53.1.71

[3] Tram, U. and Sullivan, W. (2002) Role of Delayed Nuclear Envelope Breakdown and Mitosis in Wolbachia Induced Cytoplasmic Incompatibility. Science, 296, 1124-1126. http://dx.doi.org/10.1126/science.1070536

[4] Lo, N., Paraskevoupoulos, C., Bourtzis, K., O’Neill, S.L., Werren, J.H., Bordenstein, S.R. and Bandi, C. (2007) Taxonomic Status of the Intracellular Bacterium Wolbachia Pipientis. International Journal of Systematic and Evolutionary Microbiology, 57, 654-657. http://dx.doi.org/10.1099/ijs.0.64515-0

[5] Werren, J.H. (1997) Biology of Wolbachia. Annual Reviews of Entomology, 42, 537-609. http://dx.doi.org/10.1146/annurev.ento.42.1.587

[6] Dedeine, F., Ahrens, M., Calcaterra, L. and Shoemaker, D.D. (2005) Social Parasitism in Fire Ants (Solenopsis spp.): A Potential Mechanism for Interspecies Transfer of Wolbachia. Molecular Ecology, 14, 1543-1548. http://dx.doi.org/10.1111/j.1365-294X.2005.02499.x

[7] Ahrens, M.E. and Shoemaker, D. (2005) Evolutionary History of Wolbachia Infections in the Fire Ant Solenopsis invicta. BMC Evolutionary Biology, 5, 1-5. http://dx.doi.org/10.1186/1471-2148-5-35

[8] Shoemaker, D.D., Ross, K.G., Keller, L., Vargo, E.L. and Werren, J.H. (2000) Wolbachia Infections in Native and Introduced Populations of Fire Ants (Solenopsis spp.). Insect Molecular Biology, 9, 661-673. http://dx.doi.org/10.1046/j.1365-2583.2000.00233.x

[9] Tsutsui, N.D., Kauppinen, S.N., Oyafuso, A.F. and Grosberg, R.K. (2003) The Distribution and Evolutionary History of Wolbachia Infection in Native and Introduced Populations of the Invasive Argentine ant Linepithema Humile. Molecular Ecology, 12, 3057-3068. http://dx.doi.org/10.1046/j.1365-294X.2003.01979.x

[10] Russel, J.A., Goldman-Huertas, B., Moreau, C.S., Baldo, L., Stahlhut, J.K., Werren, J.H. and Pierce, E.N. (2009) Specialization and Geografic Isolation among Wolbachia Symbionts from Ants and Lycaenid Butterflies. Evolution, 63, 624-640. http://dx.doi.org/10.1111/j.1558-5646.2008.00579.x

[11] Baldo, L., Lo, N. and Werren, J.H. (2005) Mosaic Nature of Wolbachia Surface Protein. Journal of Bacteriology, 187, 5406-5418. http://dx.doi.org/10.1128/JB.187.15.5406-5418.2005

[12] Banks, W.A., Lofgren, C.S., Jouvenaz, D.P., Stringer, C., Bishop, P.M., Williams, D.F., Wojcik, D.P. and Glances, B.M. (1981) Techniques for Collecting, Rearing and Handling Imported fire Ants. US Department of Agriculture. AAT-S-21, Washington DC, 9 p.

[13] Ahrens, M.E., Ross, K.G. and Shoemaker, D.D. (2005) Phylogeographic Structure of the Fire Ant Solenopsis invicta in 
Its Native South American Range: Roles of the Natural Barriers and Habitat Connectivity. Evolution, 59, 1733-1743. http://dx.doi.org/10.1111/j.0014-3820.2005.tb01822.x

[14] Herbert, P.D.N., Cywinska, A., Ball, S.L. and de Waard, J.R. (2003) Biological Identification through DNA Barcode. Proceedings of the Royal Society B: Biological Sciences, 270, 313-321. http://dx.doi.org/10.1098/rspb.2002.2218

[15] Hebert, P.D.N., Ratnasingham, S. and de Waard, J.R. (2003) Barcoding Animal Life: Cytochrome c Oxidase Subunit 1 Divergences among Closely Related Species. Proceedings of the Royal Society B: Biological Sciences, 270, S96-S99. http://dx.doi.org/10.1098/rsbl.2003.0025

[16] Ratnasingham, S. and Hebert, P.D.N. (2007) BOLD: The Barcode of Life System. Molecular Ecology Notes, 7, 355364. http://dx.doi.org/10.1111/j.1471-8286.2007.01678.x

[17] Martins, C., Souza, R.F. and Bueno, O.C. (2012) Presence and Distribution of the Endosymbiont Wolbachia among Solenopsis spp. (Hymenoptera: Formicidae) from Brazil and Its Evolutionary History. Journal of Invertebrate Pathology, 109, 287-296. http://dx.doi.org/10.1016/j.jip.2012.01.001

[18] Hall, T.A. (1999) BioEdit: A User-Friendly Biological Sequence Alignment Editor and Analysis Program for Windows 95/98/NT. Nucleic Acids Symposium Series, 41, 95-98.

[19] Valles, S.M. and Porter, S.D. (2003) Identification of Polygyne and Monogyne Fire Ant Colonies (Solenopsis invicta) by Multiplex PCR of Gp-9 Alleles. Insectes Sociaux, 50, 199-200. http://dx.doi.org/10.1007/s00040-003-0662-8

[20] Ross, K.G., Krieger, M.J.B. and Shoemaker, D.D. (2003) Alternative Genetic Foundations for a Key Social Polymorphism in Fire Ants. Genetics, 165, 1853-1867.

[21] Zhou, W., Rousset, F. and O’Neill, S. (1998) Phylogeny and PCR-Based Classification of Wolbachia Strains Using wsp Gene Sequences. Proceedings of the Royal Society B: Biological Sciences, 265, 509-515. http://dx.doi.org/10.1098/rspb.1998.0324

[22] Tamura, K., Dudley, J., Nei, M. and Kumar, S. (2007) MEGA 4: Molecular Evolutionary Genetics Analysis (MEGA) Software Version 4.0. Molecular Biology and Evolution, 24, 1596-1599. http://dx.doi.org/10.1093/molbev/msm092

[23] Huelsenbeck, J.P. and Ronquist, F. (2001) MRBAYES: Bayesian Inference of Phylogeny. Bioinformatics, 17, 754-755. http://dx.doi.org/10.1093/bioinformatics/17.8.754

[24] Shoemaker, D.D., Ahrens, M., Sheill, L., Mescher, M., Keller, L. and Ross, K.G. (2003) Distribution and Prevalence of Wolbachia Infections in Native Populations of the Fire Ant Solenopsis invicta (Hymenoptera: Formicidae). Environmental Entomology, 32, 1329-1336. http://dx.doi.org/10.1603/0046-225X-32.6.1329

[25] Bouwma, A.M., Ahrens, M.E., Deheer, C.J. and Shoemaker, D.D. (2006) Distribution and Prevalence of Wolbachia in Introduced Populations of the Fire Ant Solenopsis invicta. Insect Molecular Biology, 15, 89-93. http://dx.doi.org/10.1111/j.1365-2583.2006.00614.x

[26] Van Borm, S., Wenseleers, T., Billen, J. and Boomsma, J.J. (2003) Cloning and Sequencing of wsp Enconding Gene Fragments Reveals a Diversity of Co-Infecting Wolbachia Strains in Acromyrmex Leafcutter Ants. Molecular Phylogenetics and Evolution, 26, 102-109. http://dx.doi.org/10.1016/S1055-7903(02)00298-1 
Scientific Research Publishing (SCIRP) is one of the largest Open Access journal publishers. It is currently publishing more than 200 open access, online, peer-reviewed journals covering a wide range of academic disciplines. SCIRP serves the worldwide academic communities and contributes to the progress and application of science with its publication.

Other selected journals from SCIRP are listed as below. Submit your manuscript to us via either submit@scirp.org or Online Submission Portal.
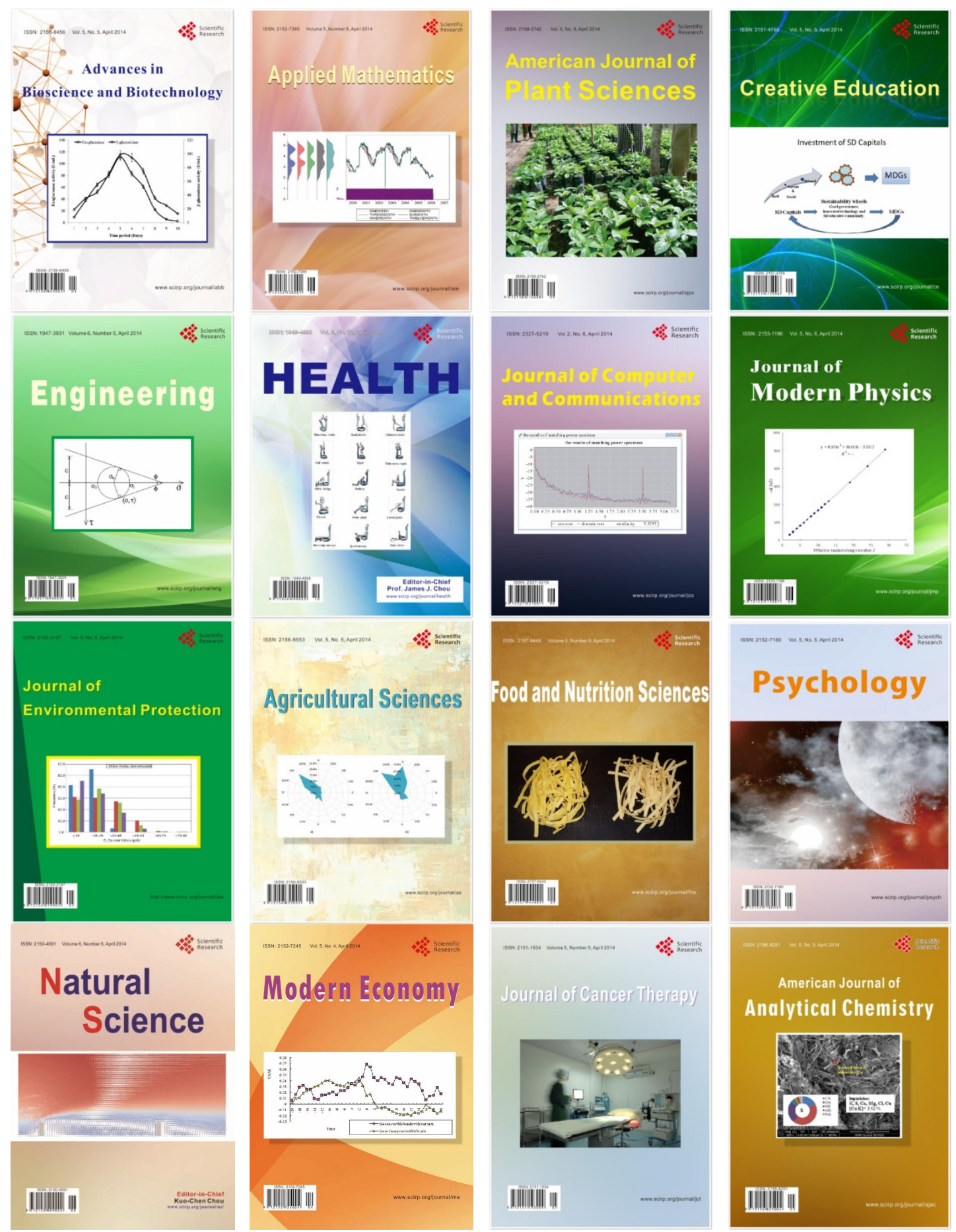